\title{
BASIC PROPERTIES OF ANTARCTIC SEA ICE AS REVEALED BY TEXTURAL ANALYSIS OF ICE CORES
}

by

\author{
Manfred A. Lange
}

(Alfred Wegener Institute for Polar and Marine Research,

Postfach 120161 , Columbusstraße, D-2850 Bremerhaven, Federal Republic of Germany)

\begin{abstract}
Sea ice constitutes a major element in the atmospheric, oceanographic and biological regime of the polar regions. Assessment of its fundamental properties requires interdisciplinary investigations on local, regional and global scales. Sea-ice structure and textural parameters of individual ice cores play a key role in such investigations. A proper characterization of sea-ice micro-structure is essential for an adequate classification of ice cores, an understanding of the growth processes of the sampled floe, and the identification of possible relationships between ice texture, and the physical, chemical and biological properties of sea ice. Investigations on ice cores which were obtained during three recent Antarctic expeditions (1983-85) in coastal waters of the eastern and southern Weddell Sea are reported. The basis for a number of physical, chemical and biological investigations is an assessment of the textural characteristics of each sea-ice core. These are derived by inspection of continuous thick sections, supplemented by an analysis of selected vertical and horizontal thin sections. Major results of this study can be summarized as follows: (i) in addition to the common ice classes, another sea-ice type, platelet ice, is identified; it is apparently unique to the coastal waters of Antarctica, near the ice-shelf edge, and (ii) different physical, chemical and biological sea-ice properties vary systematically with and are probably related to / controlled by the ice texture of the cores.
\end{abstract}

\section{INTRODUCTION}

Consolidated sea-ice cover significantly restricts or prevents the exchange of energy and matter between the atmosphere and the underlying ocean. A remarkable seasonal variation in the areal extent of Antarctic sea ice between $\sim 3$ mill. $\mathrm{km}^{2}$ and 20 mill. $\mathrm{km}^{2}$ introduces strongly varying boundary conditions in the oceanographic and atmospheric regime. This variation also affects the biological regime of the Southern Ocean. Besides causing environmental changes for many species in the water column, sea ice itself forms an ecological niche. Specially adapted micro-organisms inhabit the (brine-filled) pore space of the sea ice and provide a food source for other marine life during winter (Horner 1985).

In order to understand and quantify the relevant processes in these three regimes, a better knowledge of fundamental sea-ice properties is an essential prerequisite. The only means of studying sea ice, besides the acquisition of remote-sensing data, lies in an assessment of basic ice properties of sampled cores. Here, ice structure and textural characteristics play a dominant role. They not only provide the basis for an ice stratigraphy as a guideline for subsequent analyses and for classification of the sampled floe, but also yield information on the development of the ice cover. In addition, physical, chemical and biological properties are related to and might even be controlled by ice structure to varying degrees. It is therefore a major principle of our sea-ice program to precede other investigations by detailed structural and textural analysis whenever possible.
Despite the urgent need to obtain samples throughout the year, on local, regional and global scales, logistic constraints often impose limitations on the sampling program. In general, most ice coring is done during the summer months, which limits the areal extent of the sampling to what remains of the sea-ice cover, i.e. to the coastal regions of Antarctica.

In order to gain at least a larger areal coverage we extended our sampling program to three consecutive expeditions, which took place between 1982-83 and 1984-85. A total of about a hundred ice cores were taken during the austral summer months (January, February). Sampling was done mostly on fast ice near ice-shelf edges and on single, large floes in coastal waters of the eastern and southern Weddell Sea from $\sim 8^{\circ}$ to $60^{\circ} \mathrm{W}$ (Fig.1).

\section{EXPERIMENTAL AND ANALYTICAL DETAILS}

A major goal of the sea-ice program has been to develop a standardized sampling scheme and analytical techniques for sea-ice investigations. Such procedures, once they have been established, yield reproducible and comparable results. This is of prime importance when different data sets are to be combined. However, it is obvious that for a program which evolves over the course of several years and three expeditions this objective is not achieved immediately. This paper represents the current status of our definition of analytical procedures for sea ice core investigations. Figure 2 gives a schematic representation of these procedures.

\section{Sampling and field measurements}

Field work primarily embodies the collection of ice cores as well as a number of in-situ data. One of the difficulties in coring sea ice (as compared to fresh-water ice) is the presence of liquid brine in the sea-ice cover under field conditions (i.e. at temperatures of $>-10^{\circ} \mathrm{C}$ ). Great care has to be taken to lose as little of the brine as possible, because this significantly alters the chemical and biological properties of the cores. Hence, core handling in the field was kept to a minimum. Our usual practice is to transport the cores as soon as possible to the ship. They are stored in polyethylene bags inside closed, opaque plastic tubes at $<-28^{\circ} \mathrm{C}$. At this temperature, $\mathrm{NaCl}$ as the major constituent of the brine is solidified and thus spatially fixed.

Field measurements include: temperature profiles through the snow and ice cover, measurements of light attenuation through the ice cover and $5 \mathrm{~m}$ of the underlying water column, and thickness measurements of ice and snow (not discussed here).

\section{Structural and textural analysis}

Because of the liquid-brine problem (see above), subsequent core handling has to be done in cold-laboratories at temperatures of $<-25^{\circ} \mathrm{C}$. After removing approximately one-third of the core for archiving (Fig.2), a continuous slab of $\sim 1 \mathrm{~cm}$ thickness is cut along the entire length of the core. Such thick sections, when seen between crossed polarizers, allow a first assessment of basic structural 


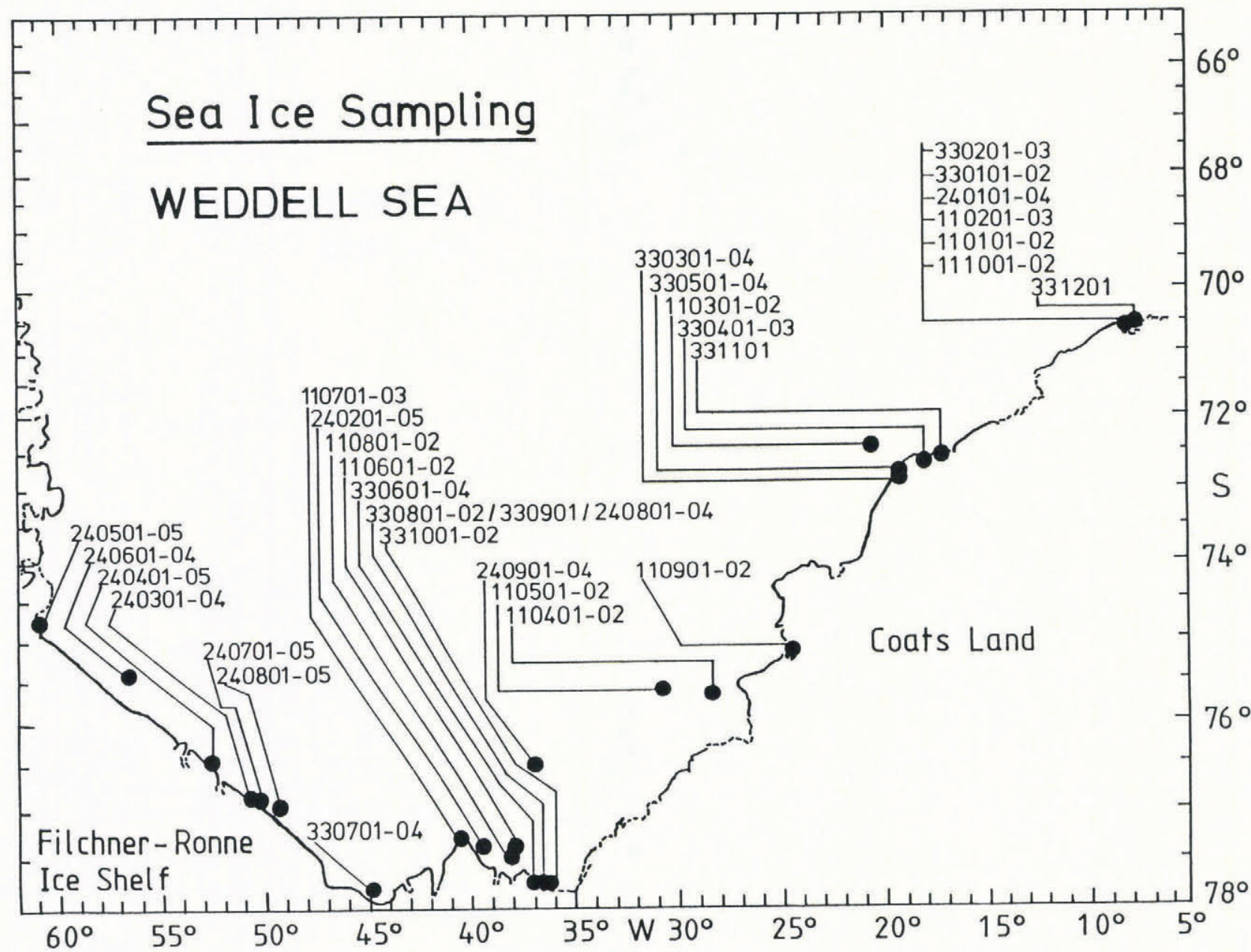

Fig.1. Map of ice-core stations in the eastern and southern Weddell Sea. Numbers represent station numbers at which at least one core was taken. The first digit stands for the years 1982-83 $(=1)$, 1983-84 (= 2), 1984-85 (= 3).

\section{Sea Ice Core Analysis}

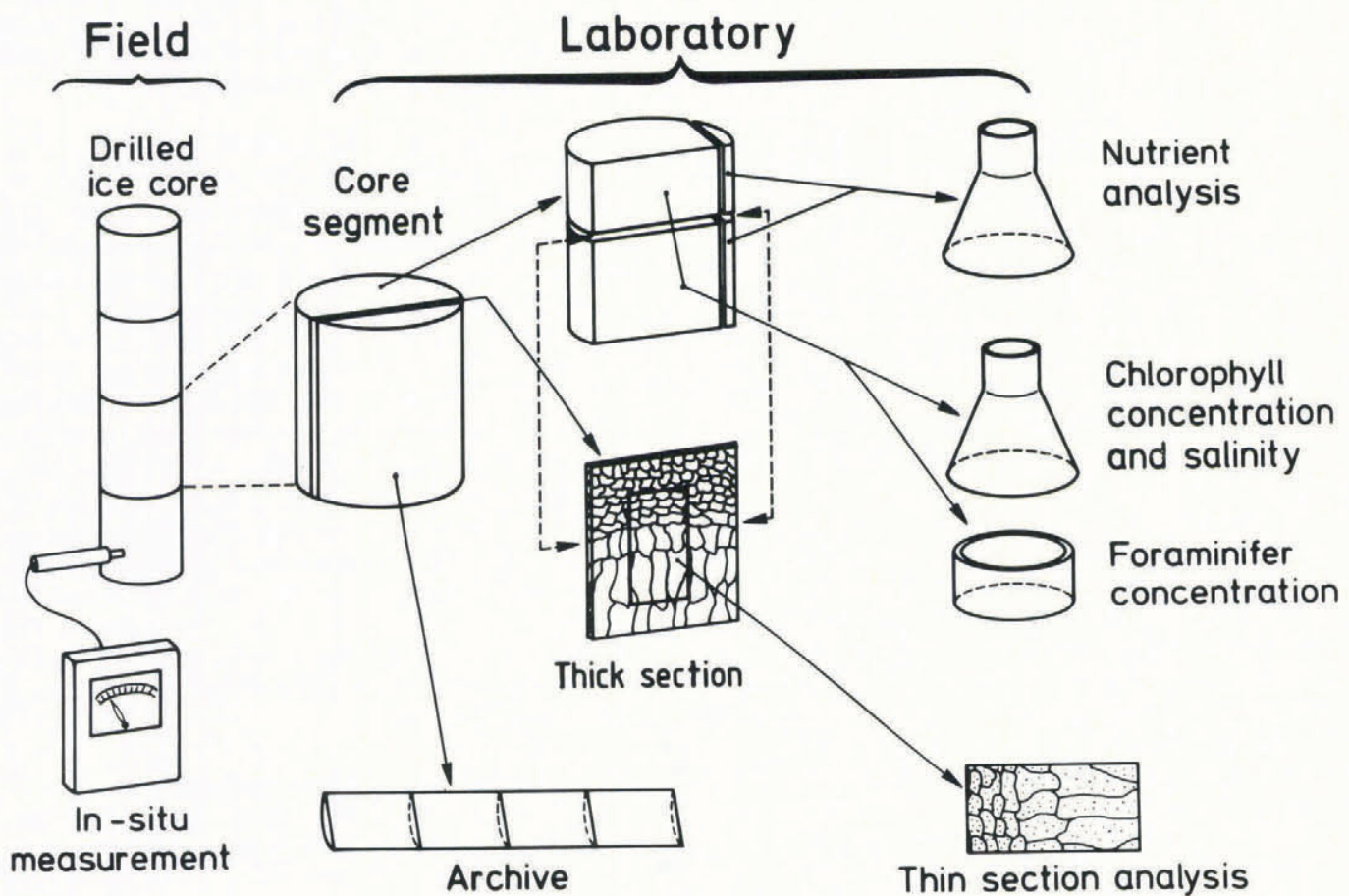

Fig.2. Schematic diagram showing the principal procedures for analyses in our sea-ice program; for further details, see text. 


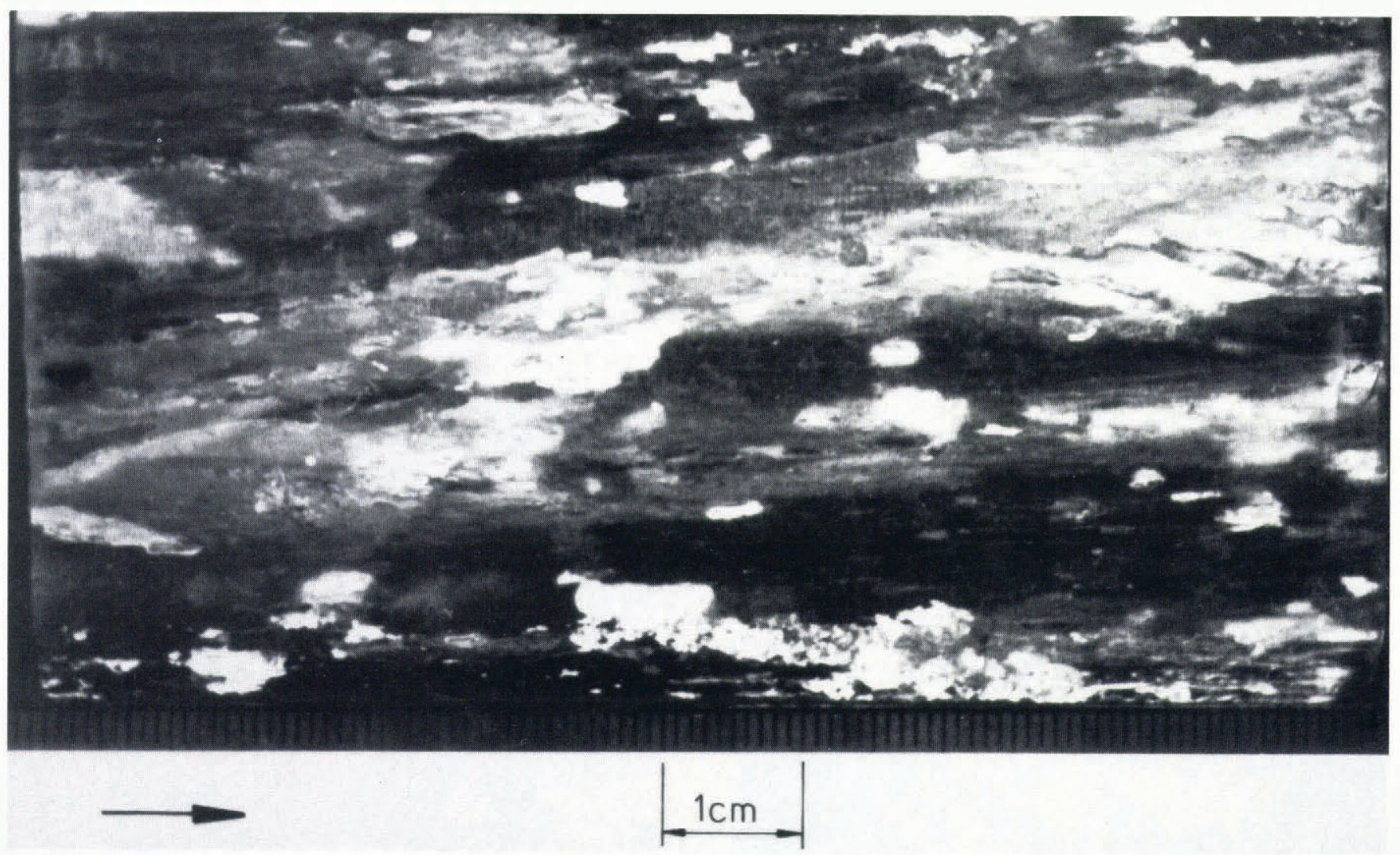

Fig.3. Vertical thick section of core AN3303101 at depth interval $0.2-0.3 \mathrm{~m}$. The arrow in this and the following figures points in the direction of the bottom of the core.

properties. Figure 3 shows a fairly uniform thick section, which is characterized by vertically elongated, relatively large grains. This core section can be classified as columnar ice.

Continuous thick-section analysis gives rise to a stratigraphic description of the sampled ice sheet by assigning a number of different ice classes to individual core sections and by identifying the transitions between these classes within the core. We have adopted the following ice classes, which are described in more detail in Weeks and Ackley (1982) and in the following section: (i) snow ice, (ii) frazil ice, (iii) columnar ice and (iv) platelet ice.

Whenever desirable, or in cases where classification based on thick sections is not possible, the thick sections are turned into thin sections by microtoming. Thin-section preparation is basically done according to techniques described by Sinha (1977). Figure 4 shows the thin version of the section of Figure 3 in cross-polarized light.

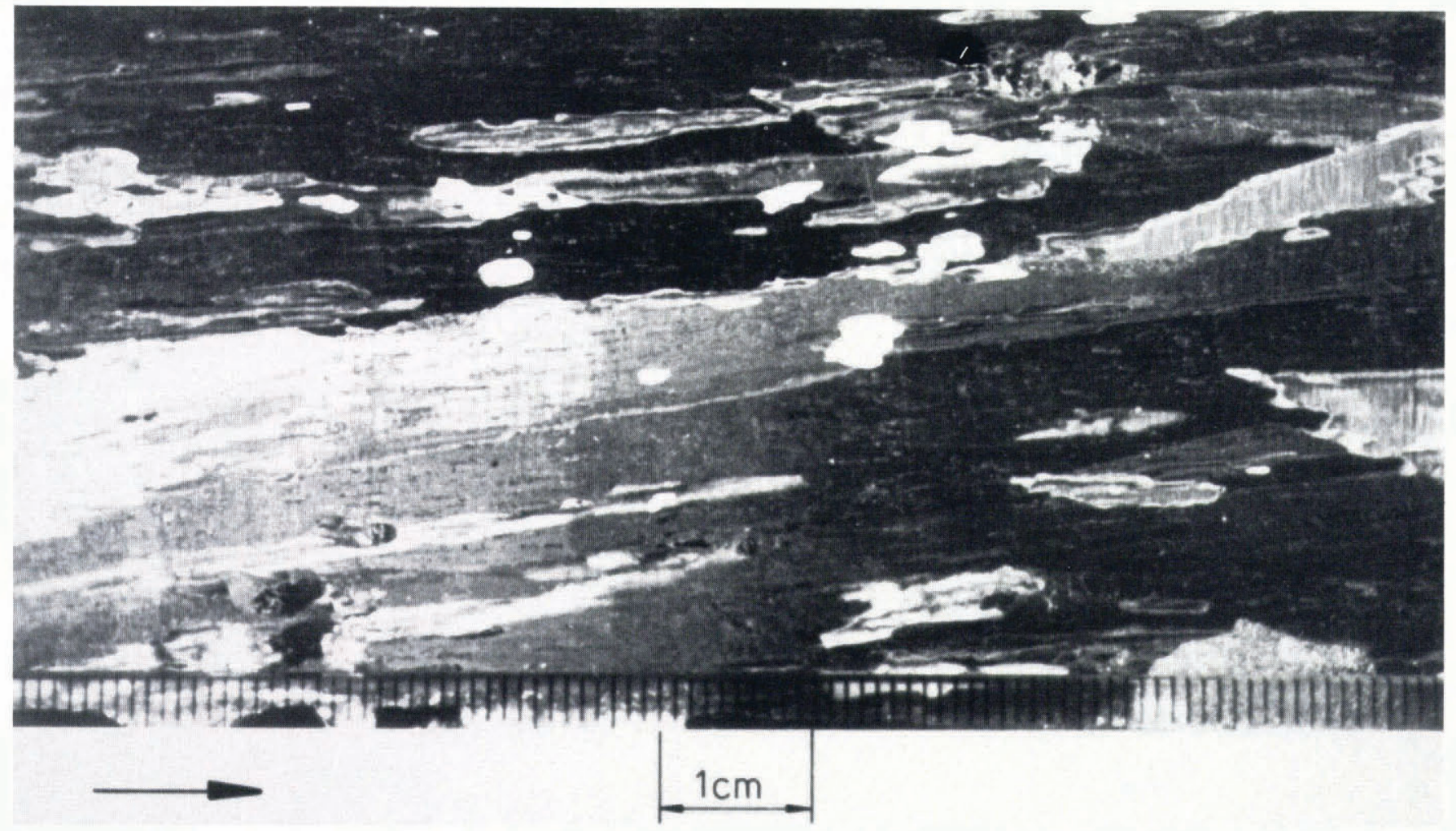

Fig.4. Vertical thin section of core AN3303101 at depth interval $0.2-0.3 \mathrm{~m}$. 
Considerably more detail is to be seen in the thin section. Not only is it now possible to identify individual grains with some certainty, but also the sub-structure of single grains, i.e. the cellular growth patterns and the brine pockets become clearly visible. Nevertheless, the basic characterization of the ice as columnar remains unchanged.

In order to perform stereographic measurements and to determine $c$-axis orientations of single grains, horizontal thin sections are fabricated at selected locations in the core. They also assist in identifying more clearly the ice classes of particularly complicated core portions. The determination of brine-layer spacings within individual grains of columnar ice in horizontal sections is a special measurement which allows estimates of ice-growth rates (Nakawo and Sinha 1984).

Thick and thin sections are documented photographically for further reference and analysis.

3. Physical, chemical and biological investigations of ice cores

Other measurements carried out on the cores include the assessment of physical properties (density, thermal conductivity, elastic parameters), chemical properties (salinity, nutrient concentrations) and biological properties (chlorophyll-a concentrations, species enumeration of silicious micro-organisms); details of these investigations are reported elsewhere (Lange and Dieckmann, in preparation). However,

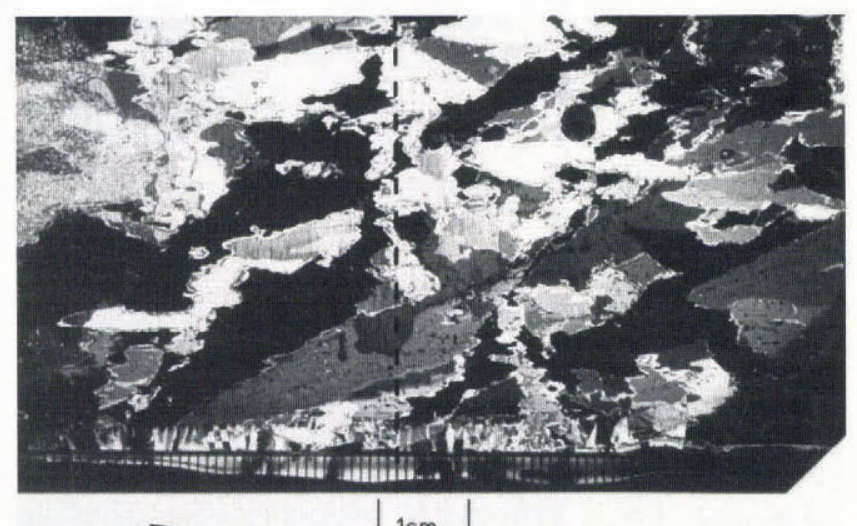

Fig.5a. Vertical thin section of core AN3303101 at depth interval $1.56-1.65 \mathrm{~m}$. The dashed line gives the position of the horizontal section in Figure $5 \mathrm{~b}$.

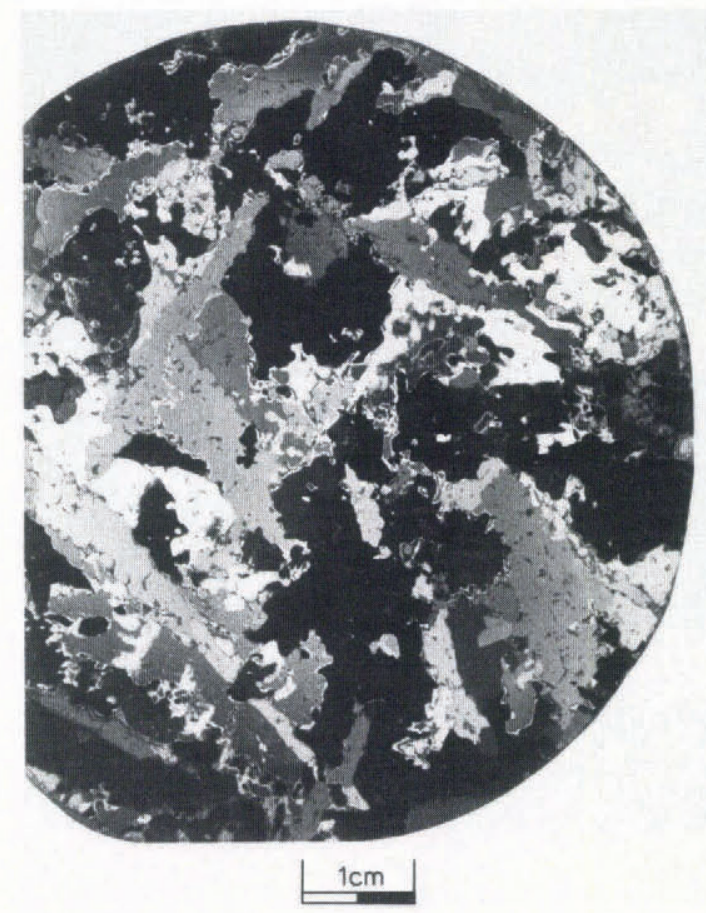

Fig.5b. Horizontal thin section of core AN3303101 at a depth of $1.6 \mathrm{~m}$. an important principle for these measurements, in our sea-ice program and in the context of this paper, is that the sample spacing is closely determined by ice stratigraphy. Instead of using arbitrary, constant-length sections, our main objective is to sample each structural unit in a core individually, regardless of the length of these units (Fig.2). Whenever the thick section, initially cut at arbitrary lengths, reveals a transition in ice structure, the corresponding ice-core segment is cut at this transition and the resulting portions are analyzed separately. This procedure allows comparisons between different measurements and the identification of possible relationships between ice texture and other ice properties.

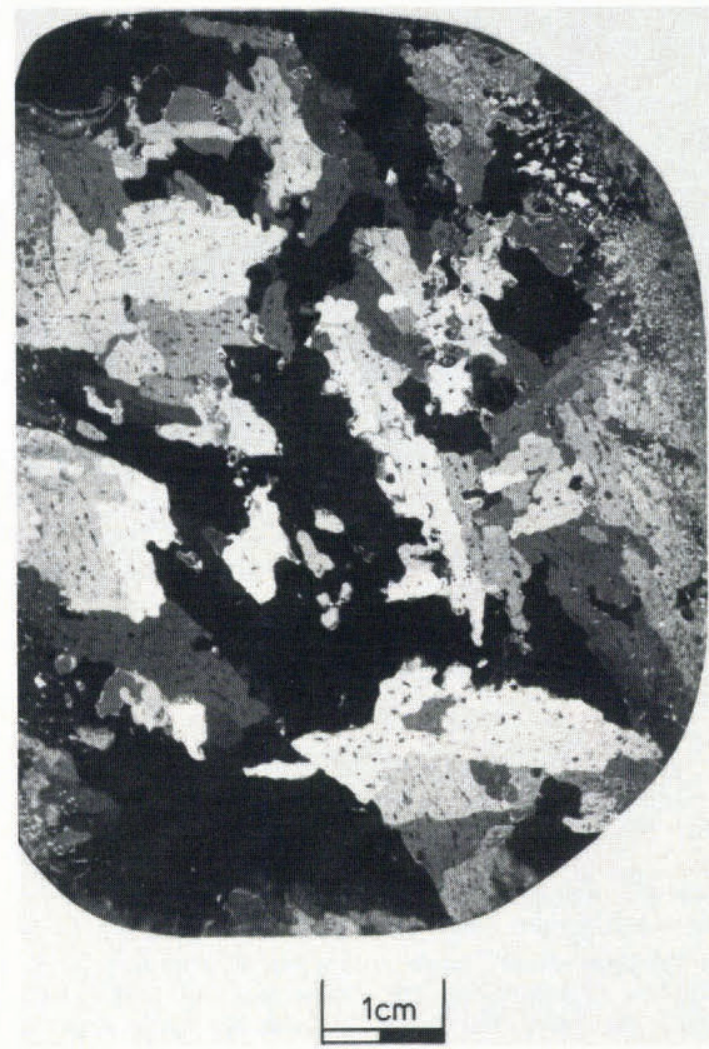

Fig.6a. Horizontal thin section of core AN3303101 at a depth of $0.4 \mathrm{~m}$.

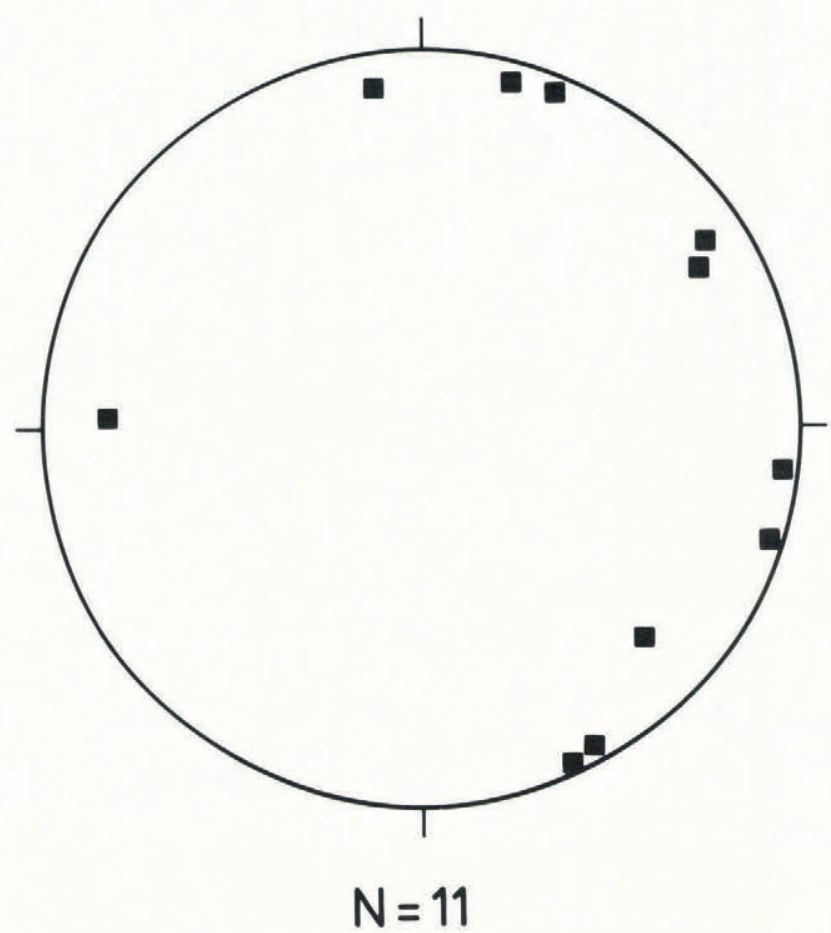

Fig.6b. $c$-axis orientation of selected grains from the thin section shown in Figure 6a. 


\section{RESULTS}

Besides the commonly recognized sea-ice types (see, e.g., Weeks and Ackley 1982), we find an additional ice class in the coastal waters of the Weddell Sea. We call this ice "platelet ice". It is described in detail by Kipfstuhl and others (in preparation). The first observations of similar textures, found in the ice of McMurdo Sound, Antarctica, were given by Paige (1966). Lewis and Weeks (1971) report on observations (primarily from Russian sources) of "underwater" ice, which also bears similarities to the platelet ice of Kipfstuhl and others (in preparation). A more recent description of platelet ice observed in Antarctica is given
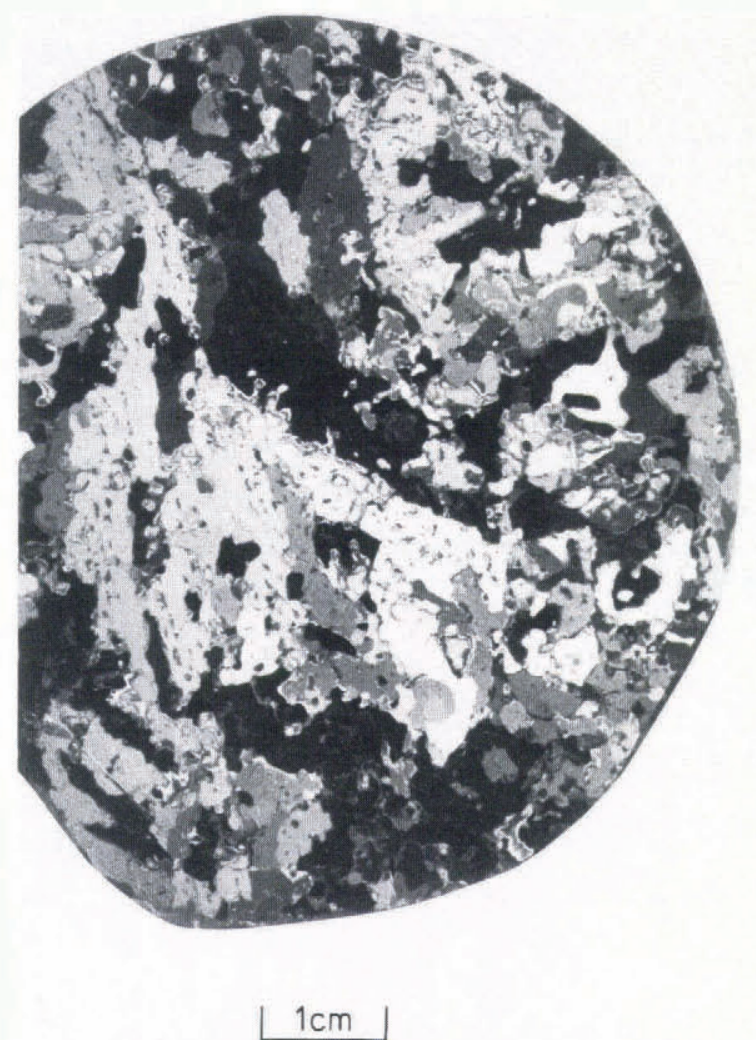

Fig.7a. Horizontal thin section of core AN3303101 at a depth of $0.88 \mathrm{~m}$.

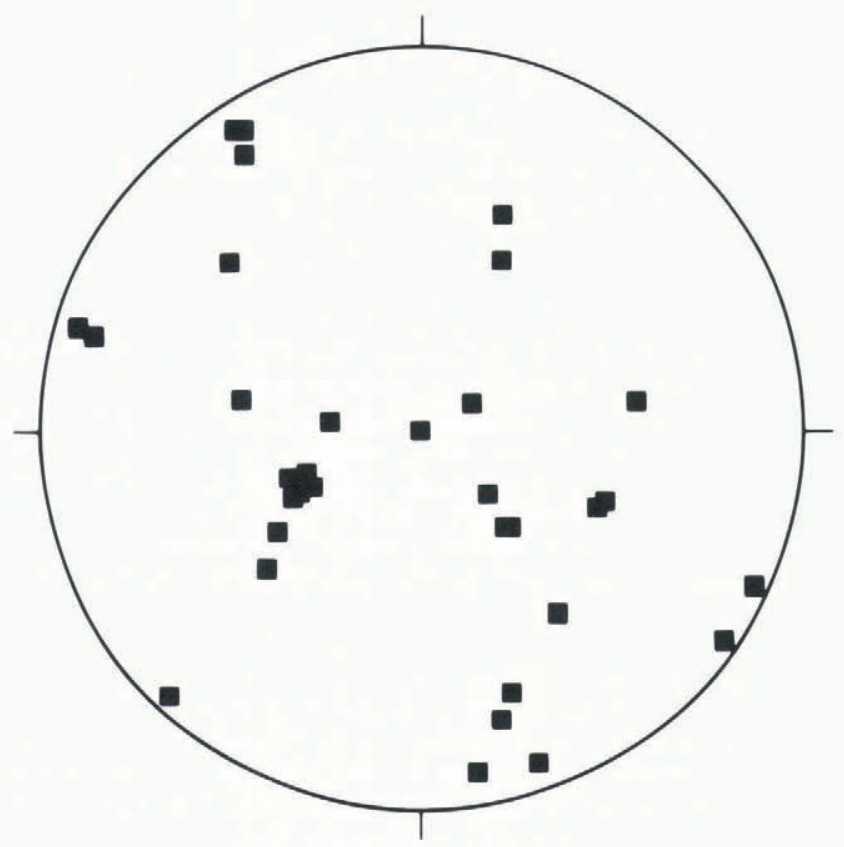

$\mathrm{N}=33$

Fig.7b. $c$-axis orientation of selected grains from the thin section shown in Figure $7 a$. by Gow and others (1982). In vertical sections, it is characterized by relatively large, elongated grains (diameters of up to a few centimeters, lengths of up to several centimeters), of ten interspersed with regions of small grains (sizes of up to a few millimeters). The grains are irregularly shaped and show no preferred orientations (Fig.5a). In thick sections, this ice type can easily be interpreted as being columnar ice, because of the apparent similarities between these two ice types. This is also true when horizontal thin sections of platelet ice are examined. They resemble, at first sight, the typically observed intergrowth structure of columnar ice (cf. Weeks and Ackley 1982). However, closer examination reveals a few very long and narrow grains, of ten running across the entire section, which are not seen in columnar ice (Fig.5b). These grains probably represent ice platelets, which may be cut vertically at an angle. An additional characteristic of platelet ice is the near-absence of any sub-structure within these large grains (e.g. brine pockets are not seen), thus indicating an origin different from that of columnar grains.

The distinctive nature of platelet ice can also be demonstrated by fabric diagrams. Figures $6 a$ and $7 a$ give two horizontal thin sections and Figures $6 \mathrm{~b}$ and $7 \mathrm{~b}$ give the orientations of $c$-axes in these sections, when plotted in an equal area net. As can be seen, $c$-axes in Figure $6 \mathrm{~b}$ show a remarkable bias towards horizontal orientations, which is typical for columnar ice (cf. Weeks and Ackley 1982). The axes in Figure $7 \mathrm{~b}$, on the other hand, lack this bias in orientations, thus indicating that this section represents platelet ice and not columnar ice.

Portions of platelet ice occur in layers of different thicknesses (from a few centimeters to a few tenths of a centimeter) scattered over the entire length of the cores, but primarily in the bottom quarter. The origin of this ice type is still unresolved. Moretskiy (1968) and Kipfstuhl and others (in preparation) report the occurrence of a layer of unconsolidated ice platelets underneath existing sea-ice cover Such layers reach thicknesses of a few meters and extend outwards for several hundred of meters, or even a few kilometers, from the edges of ice shelves. Indivual platelets measure several centimeters in diameter and a few millimeters in thickness. When a layer of such platelets becomes consolidated and part of the ice cover, textures such as those identified as platelet ice are conceivable.

The total volume fraction of platelet ice in a given ice core may reach $40 \%$. Tentative total mean concentrations of different ice types in the coastal waters of the Weddell Sea can be given as follows (in volume per cent): snow ice = $5-10$, frazil ice $=50-60$, columnar ice $=20-30$, platelet ice $=20-30$.

The spacing of brine layers as seen in horizontal thin sections of columnar grains is an empirical measure of the growth velocity of the ice (Nakawo and Sinha 1984). Figure 8 represents a systematic assessment of brine-layer spacings over a large part of an ice core. Also shown are salinity values for $10 \mathrm{~cm}$ sections and a representation of the ice stratigraphy of the core. Despite the large error bars and the scatter in the data, a distinct pattern of brine-layer spacings as a function of depth is to be seen, related to ice texture and the salinities. Small and large spacings between brine layers correspond to small and large grain sizes and to large and small salinity values respectively. This is in accordance with the findings of Nakawo and Sinha (1984) and can be used to derive growth rates based on an empirical relation given by these authors (not shown here). Even though this technique needs a more solid foundation, to be provided either by theory or by more field data, it offers an opportunity to relate the ice cover to the oceanographic and atmospheric regimes which prevailed during its formation.

Figure 9 shows ice texture and a number of chemical and biological properties as a function of depth for an ice core. This represents a typical example and demonstrates the close correlation of ten seen between these quantities. Despite the fact that the exact nature of these correlations remains to be determined, the existence and consistency of such trends is encouraging. However, they are seen only when combined investigations are carried out, by using ice stratigraphy as the guideline for the sample spacing. 
Salınity, \%० Ice texture Brine layer spacing. $10^{-4} \mathrm{~m}$

010
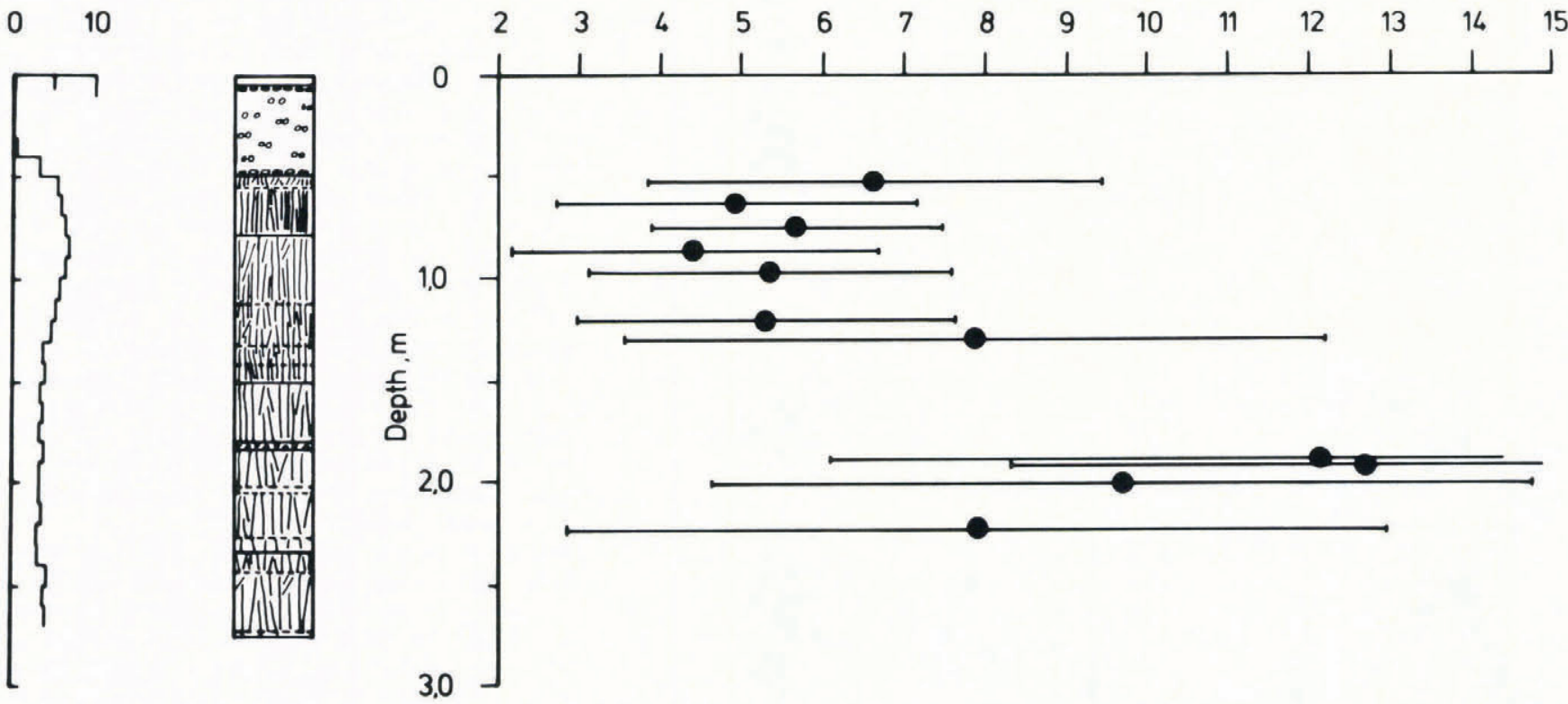

Fig.8. Salinity, ice texture and brine-layer spacing of core AN2402101 as a function of depth. The sections with near-vertical line-signature represent columnar ice, those with open circles represent frazil ice in the ice-texture diagram. The spacing of lines in the columnar ice signature is a representation of relative grain sizes in each core. Solid and dashed horizontal lines in the structural cartoon represent boundaries between different ice textures and changes in characteristics within individual textural units respectively.

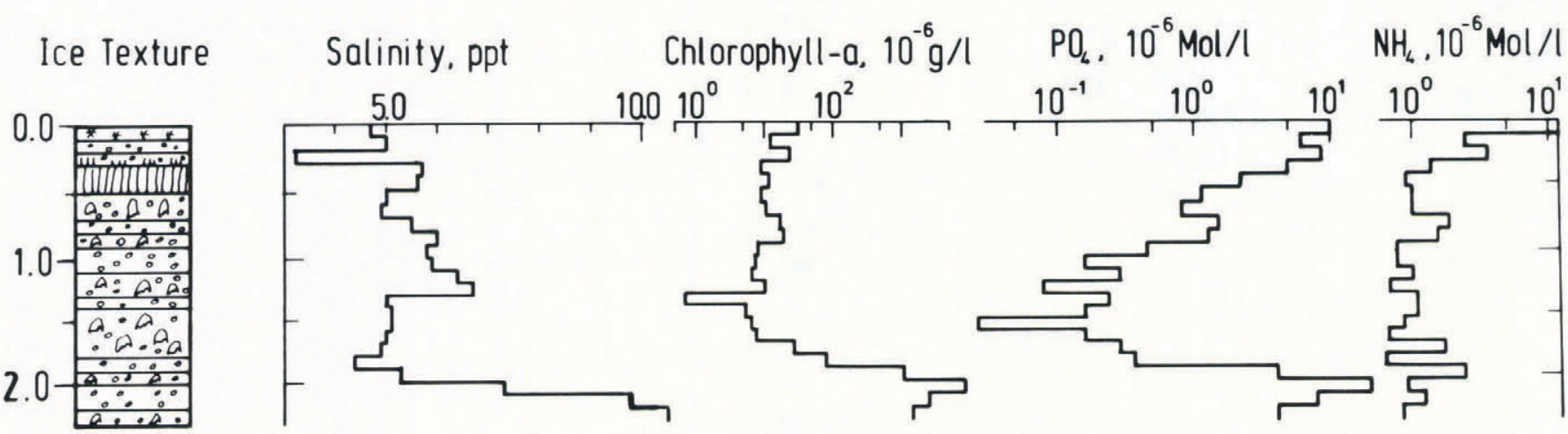

Depth, m

Fig.9. Ice texture, chemical and biological properties of core AN3303101 as a function of depth. The top signature in the ice-texture diagram represents snow ice and the larger, irregularly shaped symbols among the open circles represent platelet ice. For other symbols, see caption to Figure 8 .

\section{CONCLUSIONS}

Textural characteristics, as obtained from the study of ice cores, play a dominant role in the assessment of fundamental sea-ice properties. They provide a means of determining a stratigraphic description of, as well as meaningful sample spacing for, subsequent physical, chemical and biological analyses of ice cores. Only in conjunction with ice texture does sample spacing reveal possible relationships between these quantities and the microstructure of the sampled ice. Even though their exact nature has not yet been explained, our data clearly demonstrate the existence and consistency of such relationships.

Thin-section analysis assists in defining more clearly ice classes of particular core sections. It also provides the basis for detailed stereographic measurements and the determination of the $c$-axis orientation of single grains. The mean brine-layer spacing as a function of depth, as obtained from horizontal thin sections of columnar core portions, allows growth rates of the analyzed ice cover to be estimated. This has been demonstrated for Arctic ice by
Nakawo and Sinha (1984) and has also been observed in our samples from the eastern and southern Weddell Sea.

Besides the snow-, frazil- and columnar ice commonly found, an additional ice type, which we call platelet ice, has been found in the coastal waters of the Weddell Sea. This ice is apparently unique to this particular oceanographic regime and its origin is probably related to processes underneath and in the vicinity of ice-shelf edges.

\section{ACKNOWLEDGEMENTS}

Many colleagues have contributed to the sea-ice sampling program, in particular Dr G Dieckmann; their help is greatly appreciated. I should like to thank $\mathrm{H}$ Eicken and J Kipfstuhl for many stimulating and fruitful discussions on textural analysis in general and on the nature of platelet ice in particular. I thank $\mathrm{Dr} G$ Dieckmann for his constructive criticism of a draft version of this paper. This is contribution no. 48 of the Alf red Wegener Institute for Polar and Marine Research, Bremerhaven, Federal Republic of Germany. 


\section{REFERENCES}

Gow A J, Ackley S F, Weeks W F, Govoni J W 1982 Physical and structural characteristics of Antarctic sea ice. Annals of Glaciology 3: 113-117

Horner R A (ed) 1985 Sea ice biota. Boca Raton, FL, CRC Press

Lewis E L, Weeks W F 1971. Sea ice: some polar contrasts. In Deakon, Sir George (ed) Symposium on Antarctic Ice and Water Masses, Tokyo, Japan, 19 September 1970. [Cambridge], Scientific Committee on Antarctic Research: 23-34

Moretskiy V N 1965 Morskoy vnutrivodnyy led [Frazil ice at sea]. Problemy Arktiki i Antarktiki 19: 32-38

Nakawo M, Sinha N K 1984 A note on brine layer spacing of first-year sea ice. Atmosphere-Ocean 22(2): 193-206

Paige R A 1966 Crystallographic studies of sea ice in McMurdo Sound, Antarctica. Port Hueneme, CA, US Naval Civil Engineering Laboratory (Technical Report R494)

Sinha N K 1977 Technique for studying structure of sea ice. Journal of Glaciology 18(79): 315-323

Weeks W F, Ackley S F 1982 The growth, structure and properties of sea ice. CRREL Monograph 82-1 